\title{
Promoting Engineering Persistence Among Women through Alignment of Occupational Values and Perceptions of the Field
}

\section{Dr. Joni M Lakin, Auburn University}

Joni M. Lakin, Ph.D. from The University of Iowa, is Assistant Professor of Educational Foundations, Leadership, and Technology at Auburn University. Her research interests include educational assessment, educational evaluation methods, and increasing diversity in STEM fields.

\section{Dr. Edward W. Davis, Auburn University}

Edward W. Davis received his PhD from the University of Akron in 1996. He worked in the commercial plastics industry for 11 years, including positions with Shell Chemicals in Louvain-la-Nueve Belgium and EVALCA in Houston TX. He joined the faculty at Auburn University in the fall of 2007. In 2014 he was promoted to Senior Lecturer. He has regularly taught courses in three different engineering departments. In 2015 he began his current position as an Assistant Professor in the Materials Engineering Program.

\section{Prof. Virginia A. Davis, Auburn University}

Dr. Virginia A. Davis' research is primarily focused on using fluid phase processing to assemble cylindrical nanomaterials into larger functional materials. Targeted applications include optical coatings, 3D printed structures, light-weight composites, and antimicrobial surfaces. Her national awards include selection for the Fulbright Specialist Roster (2015), the American Institute of Chemical Engineers Nanoscale Science and Engineering Forum's Young Investigator Award (2012), the Presidential Early Career Award for Scientists and Engineers (2010), and a National Science Foundation CAREER Award (2009). Her Auburn University awards include the Excellence in Faculty Outreach (2015), an Auburn University Alumni Professorship (2014), the Auburn Engineering Alumni Council Awards for Senior (2013) and Junior (2009) Faculty Research, the Faculty Women of Distinction Award (2012), and the Mark A. Spencer Creative Mentorship Award (2011). Dr. Davis is the past chair of Auburn's Women in Science and Engineering Steering Committee (WISE) and the faculty liaison to the College of Engineering's 100 Women Strong Alumnae organization which is focused on recruiting, retaining and rewarding women in engineering. She was also the founding advisor for Auburn's SHPE chapter. Dr. Davis earned her Ph.D. from Rice University in 2006 under the guidance of Professor Matteo Pasquali and the late Nobel Laureate Richard E. Smalley. Prior to attending Rice, Dr. Davis worked for eleven years in Shell Chemicals' polymer businesses in the US and Europe. Her industrial assignments included manufacturing, technical service, research, and global marketing management; all of these assignments were focused on enabling new polymer formulations to become useful consumer products. 


\title{
Promoting Engineering Persistence among Women Through Alignment of Occupational Values and Perceptions of the Field
}

\begin{abstract}
This paper explores the relationship between students' occupational values and their perceptions of engineering as a career field and how this relationship impacts major commitment. Research has documented substantial sex differences in occupational values and interests, where women are more likely to prefer communal or helping occupations while men are more likely to prefer individualistic or status-affording occupations. Researchers theorize that commitment to a college major is supported when there is an alignment between personal values and the value affordances of the career fields (i.e., what values the fields can meet). Fields such as engineering are often seen as only affording the pursuit of status goals. In this study, we explored whether male and female engineering students varied in the degree to which they believed engineering was a communal vs. status profession, assessed their occupational values, and explored how both constructs predicted commitment to their engineering major.
\end{abstract}

\section{Introduction}

Understanding how and why college students develop commitment to a career field is important to developing programs that support students' academic development and career planning. Fields like engineering seem to struggle more than other fields to retain promising students through graduation. ${ }^{1}$ Therefore, research exploring how students develop commitment to engineering is of particular interest. This issue is especially important when considering the widespread goal of increasing the diversity of engineering and promoting the success of diverse student populations in this field.

To better understand career commitment, this research paper explores the relationship between students' occupational values and their perceptions of engineering as a career field and how this relationship impacts major commitment. Research has documented substantial sex differences in occupational values and interests, where women are more likely to prefer communal or helping occupations while men are more likely to prefer individualistic or statusaffording occupations ${ }^{2,3}$ Researchers theorize that commitment to a college major is supported when there is an alignment between personal values and the value affordances of the career fields (i.e., perceptions of which values the field can meet). Therefore, sex differences in values may help explain a lack of commitment to engineering if there is a mismatch between values and students' perceptions of the value affordances of engineering. ${ }^{4,5,6}$

Researchers in science, technology, engineering, and mathematics (STEM) education have begun to explore whether these sex differences in career preferences and values can help explain existing sex differences in the choice of STEM college majors. ${ }^{4}$ In contrast, the value affordances of different career fields have been viewed as fixed characteristics of fields. For example, fields like engineering have been considered only to afford the pursuit of individualistic/status goals and not communal/helping goals. Therefore, these fields have been seen to be incompatible with women's more typical occupational values profile. However, new research indicates there may be substantial individual differences in the perception of value 
affordances of different career fields. ${ }^{5}$ Furthermore, some intervention research has shown that this perception can be modified through educational activities to increase women's interest in engineering. ${ }^{6}$

\section{Public Relations Campaigns}

This line of research is critical because the field of engineering, led by the National Academy of Engineering, is making increasing efforts to portray engineering as an important and exciting field of study that has profound impacts on society (e.g., "Changing the Conversation", "Grand Challenges", and "Messaging for Engineering"7,8,9,10). These efforts are intended to address various challenges to the field of engineering. Among those challenges are, first, a lack of interest in engineering among U.S. college students that limits the number of U.S.-citizen students entering undergraduate and graduate engineering programs. ${ }^{1}$

Second, the campaigns address a nationally perceived need to increase the diversity of students engaging in engineering majors, in terms of gender, race/ethnicity, and socioeconomic status. $^{11,12,13}$ To address both of these issues, the Changing the Conversation campaign and other efforts are intended to correct a perceived mismatch between some students' preference for careers that serve a communal or altruistic career goal and the affordances of engineering, which may be perceived as a field that offers more opportunity to fulfill status and individualistic values than altruistic and communal values. The NAE campaigns are therefore designed to challenge common perceptions of engineering's value affordances and increase the number and diversity of students interested in engineering college majors and careers.

The underlying theory of these campaigns is based on three assumptions: (1) perception of career affordances is malleable to intervention, (2) underrepresented groups differ in these perceptions or their personal values, and (3) retention in engineering among underrepresented groups can be promoted through value-affordances alignment. However, these theoretical links have are supported by little empirical research.

\section{Current Study}

In this study, we explored whether male and female engineering students varied in the degree to which they believed engineering was a communal vs. individualistic profession, assessed their occupational values in terms of status vs. altruistic goals, and explored how both constructs predicted commitment to an engineering major. We addressed the following questions:

1. Do first-year engineering students show sex differences in occupational values and beliefs about engineering?

2. Do engineering perceptions or personal career values correlate with commitment to an engineering major?

3. Are these relationships present in a latent model?

\section{Methods}

This study used a causal-comparative quantitative design to compare differences in the focal constructs (values, perceptions of engineering, and commitment to engineering) between 
men and women. We administered a survey on engineering attitudes to a large sample of firstyear students enrolled in a pre-engineering introductory course at a large four-year, research focused institution. The survey, which was administered as part of a larger project, included scales related to students' attitudes about engineering. In addition, we asked demographic question (race/ethnicity, gender, etc.). Two semesters of students have completed the survey.

\section{Participants}

The focal university offers a pre-engineering course designed to offer students an opportunity to learn more about the key concepts in their intended major as well as help them develop or review the fundamental skills needed for advanced engineering coursework. To gather a representative sample of the pre-engineering majors at this university, we therefore approached the instructors of this course (required for all pre-engineering majors) to invite their students to participate. This survey occurred within the first two weeks of the semester and was conducted (within the exception of one instructor) online.

Over the course of two semesters, roughly half of the 10 to 12 course instructors allowed us to survey their students. A total of 429 students completed the survey, including 217 in the spring semester and 212 in the fall. According to institutional records, around 1,200 first-time freshmen enroll in Engineering each year, so, excluding transfer students, this represents approximately one-third of eligible students. Most faculty used the online survey for their students, while one exclusively used the paper survey. Several professors gave course credit for completing the online survey. As a result of these procedures, this sample likely excludes students who are not attending their pre-engineering classes regularly or those who do not monitor their course site, which could include less motivated or committed engineering students.

Along with the attitude scales, students were asked to report their gender, race, and whether they were a first-year student, transfer student, or other (occasionally students do not take this course until their second year at the university). Table 1 shows the percent of students in each category.

Table 1: Descriptive statistics of sample

\begin{tabular}{llrr}
\hline Demographic variable & N & Percent \\
\hline Gender & Female & 131 & 30.3 \\
& Male & 298 & 69.0 \\
\hline \multirow{2}{*}{ Race } & African-American or Black & 21 & 4.9 \\
& Asian or Pacific Islander & 16 & 3.7 \\
& White & 366 & 85.9 \\
& Other or Multi-racial & 23 & 5.3 \\
\hline \multirow{2}{*}{ Ethnicity } & Not Hispanic & 409 & 94.9 \\
& Hispanic & 18 & 4.2 \\
\hline \multirow{2}{*}{ Enrollment } & Freshman & 325 & 75.8 \\
& Transfer & 62 & 14.4 \\
& Other & 42 & 9.8 \\
\hline
\end{tabular}

Note. Some missing data affects the specific counts. 
Typical of most engineering programs, the student makeup was predominantly white and Asian (88\%), while just $12 \%$ came from underrepresented minority groups. About $30 \%$ of the students were female, which is also typical of engineering fields, although a bit high for this institution (the freshman engineering class at this university was 18\% female). As expected, $76 \%$ of respondents were first year students, while $14 \%$ were transfer students. Participating faculty came from a range of engineering programs including Biosystems, Chemical, Industrial and Systems, Mechanical, Polymer and Fiber, and Computer Science and Software Engineering.

\section{Instruments}

A battery of attitude scales was assembled for the purposes of this study from the literature. The first 17-item scale assessed students' Beliefs about Engineering, with half of the items reflecting beliefs related to engineering as a helping or communal profession (e.g., "Engineers are helping to solve challenging problems.") and seven related to status (e.g., "Engineers are well paid."). Three items about how interesting engineering was were included to obscure the two focal scales. This scale was assembled from several common engineeringrelated attitude scales. ${ }^{12,14,15}$ These items were presented with a four-point rating scale: strongly disagree, somewhat disagree, somewhat agree, and strongly agree. In this sample, the subscales had acceptable internal consistency estimates (See Table 2.)

Occupational values (or work values) were assessed using an 11-item scale adapted from prior research. ${ }^{5}$ It used the same four-point scale as the Beliefs measure and reflected values related to individualistic or status values (e.g., "having status or power") as well as altruistic or communal values (e.g., "helping others"). Again, two unrelated items (related to fun and creativity) were included to distract from the focal scales.

In addition to assessing attitudes towards engineering as a field, we also asked four questions about commitment to staying in an engineering major. These items were modified from those used by Perez et al. ${ }^{16}$ (their items refer to STEM majors and ours were revised to refer only to engineering). An example item is "I am likely to remain in my engineering major to graduation." These items also used a four-point scale of Strongly Disagree to Strongly Agree.

Cronbach's alphas for the focal scales were moderate. We used Exploratory Factor Analysis to determine that this was the most appropriate organization of items. Removing items or reorganizing them did not increase the internal consistency estimate. Confirmatory Factor Analysis was used to further explore the factor structure and alignment of items with scales.

\section{Analysis}

Analysis began with descriptive statistics. We then compared the attitude scales across male vs. female students using independent t-tests. T-tests between genders and correlations between the scales were explored.

After inspecting the survey data, non-normality was a concern. Therefore, instead of a standard multiple regression, which could be biased by non-normality, we explored the latent structure of the variables. We used MPlus 7 which offers the MLM estimator that is robust in analyses with non-normal variables. ${ }^{17}$ 
Table 2: Details about Attitude Measures

\begin{tabular}{|c|c|c|c|c|c|}
\hline Scale & $\begin{array}{l}\text { Primary } \\
\text { Source }\end{array}$ & Sub-Scale & Example item & $\begin{array}{l}\# \\
\text { items }\end{array}$ & $\begin{array}{l}\text { Cronbach's } \\
\alpha\end{array}$ \\
\hline \multirow[t]{3}{*}{$\begin{array}{l}\text { Beliefs about } \\
\text { Engineering }\end{array}$} & \multirow[t]{3}{*}{$\begin{array}{l}\text { Litzler \& } \\
\text { Lorah }^{12}\end{array}$} & $\begin{array}{l}\text { Altruistic/ } \\
\text { Helping profession }\end{array}$ & $\begin{array}{l}\text { Engineers help to make the } \\
\text { world a better place. }\end{array}$ & 7 & 0.73 \\
\hline & & Status & $\begin{array}{l}\text { Society values the work } \\
\text { engineers do. }\end{array}$ & 7 & 0.64 \\
\hline & & Interesting field ${ }^{\mathrm{a}}$ & $\begin{array}{l}\text { I expect that engineering will be } \\
\text { a rewarding career. }\end{array}$ & 3 & 0.33 \\
\hline \multirow[t]{3}{*}{$\begin{array}{l}\text { Occupational } \\
\text { Values }\end{array}$} & \multirow[t]{3}{*}{$\begin{array}{l}\text { Diekman } \\
\text { et al. }{ }^{5}\end{array}$} & $\begin{array}{l}\text { Communal/ } \\
\text { Altruistic }\end{array}$ & Serving humanity & 4 & 0.78 \\
\hline & & & Having power or influence & 5 & 0.68 \\
\hline & & Creativity/Fun ${ }^{\mathrm{a}}$ & Using creativity & 2 & $0.53^{\mathrm{a}}$ \\
\hline $\begin{array}{l}\text { Engineering } \\
\text { Commitment }\end{array}$ & $\begin{array}{l}\text { Perez } \\
\text { et al. }{ }^{16}\end{array}$ & -- & $\begin{array}{l}\text { I am likely to remain in my } \\
\text { engineering major to } \\
\text { graduation. }\end{array}$ & 4 & 0.66 \\
\hline
\end{tabular}

Notes. ${ }^{\text {a }}$ These items were included as filler so the two scales are not as obvious.

Confirmatory Factor Analysis (CFA) and path analysis was used to further explore the latent structure of the survey scales and the relationship between the constructs of interest (beliefs, values, and commitment). To understand sex differences in the latent measurement model, we used a multi-group comparison of measurement models to compare models that are increasingly constrained across the two groups. ${ }^{18,19}$ The following steps were used:

0 . Fit a common model in each group separately

1. Fit a common model to all groups simultaneously with all parameters freely estimated

2. Constrain factor loadings of items on factors

3. Constrain item error variances

4. Constrain factor variances

5. Constrain factor covariances

6. Free constraints on factor means

At each step, adequate model fit was a prerequisite for constraining additional parameters in later steps (i.e., if factor variances are not equivalent, then factor covariances were not constrained).

The fit of individual models were assessed using a variety of fit indices including the Comparative Fit Index (CFI), Root Mean Square Error of Approximation (RMSEA), and the Standardized Root Mean Square Residual (SRMR). For the TLI and CFI indices, a value above .90 is acceptable and a value above .95 is good. ${ }^{19} \mathrm{CFI}$ includes a penalty for additional parameters. For RMSEA, an estimate and confidence interval that stay below .05 are optimal. ${ }^{20}$ For SRMR, a value below .08 is good. ${ }^{19}$ Improvements in fit for nested models were tested using Change in $\mathrm{X}^{2}$ tests and by inspecting Akaike Information Criterion (AIC) and Bayesian Information Criterion (BIC). For the AIC and BIC, lower values indicate better fit for a model. The BIC indicator includes a stronger penalty for additional parameters compared to AIC to discourage over-fitting the model. ${ }^{19}$ 


\section{Results}

Inspection of descriptive statistics as well as histograms indicated that several of the focal variables (which were average composite scores of the corresponding rating scale items) were non-normally distributed, with a negative skew and many scores at or near the scale maximum. Skew was greatest on altruistic beliefs and values as well as commitment. This degree of skew can bias statistical results. Rather than manipulate distributions to create normally distributed variables, we conducted traditional analyses using manifest variables and then latent modeling with statistical methods that allowed for non-normal variables to confirm our results with unbiased estimates.

\section{Sex differences}

We used t-tests and Cohen's d effect sizes to assess mean differences between men and women in their beliefs about engineering, occupational values, and commitment to engineering. As expected, we found sex differences in career values, with men showing statistically higher status values $(d=-0.29)$ and women having significantly higher altruism values $(d=0.35)$. There were no significant differences in beliefs about engineering or commitment to the major. ${ }^{i}$

Table 3: Sex differences in Means

\begin{tabular}{lllllll}
\hline \multirow{2}{*}{ Variable } & \multicolumn{2}{l}{$\begin{array}{l}\text { Female } \\
(\mathrm{N}=131)\end{array}$} & \multicolumn{2}{l}{$\begin{array}{l}\text { Male } \\
(\mathrm{N}=298)\end{array}$} & \multicolumn{2}{c}{ Sex diffs } \\
\cline { 2 - 7 } & $\mathrm{M}$ & $\mathrm{SD}$ & $\mathrm{M}$ & $\mathrm{SD}$ & $\mathrm{t}(427)$ & $\mathrm{d}$ \\
\hline Beliefs-Status & 2.37 & 0.34 & 2.32 & 0.40 & 1.159 & 0.13 \\
Beliefs-Altruism & 2.68 & 0.36 & 2.62 & 0.41 & 1.484 & 0.16 \\
Value-Status & 1.72 & 0.53 & 1.88 & 0.55 & $\mathbf{- 2 . 8 1 * *}$ & $\mathbf{- 0 . 2 9}$ \\
Value-Altruism & 2.29 & 0.66 & 2.06 & 0.63 & $\mathbf{3 . 3 0} * *$ & $\mathbf{0 . 3 5}$ \\
Commitment & 2.38 & 0.61 & 2.39 & 0.54 & -.240 & -0.02 \\
\hline
\end{tabular}

Note. $* \mathrm{p}<.05, * * \mathrm{p}<.01$

\section{Correlations with Commitment to Engineering}

Table 4 shows that the patterns of correlations appeared to differ for men and women. Men's commitment to an engineering major was significantly predicted by status values $(\mathrm{r}=$ .13). For women, significant predictors of commitment included altruism beliefs $(r=.20)$ and altruism values $(r=0.17)$. Correlations were modest, however.

Beliefs about status and altruism were highly correlated for both groups, indicating that responses may reflect a generally positive or negative view of engineering that affects both scales. Correlations between values were more modest. 
Table 4: Correlations by Gender

\begin{tabular}{llllll}
\hline & $\begin{array}{l}\text { Beliefs- } \\
\text { Status }\end{array}$ & $\begin{array}{l}\text { Beliefs- } \\
\text { Altruism }\end{array}$ & $\begin{array}{l}\text { Value- } \\
\text { Status }\end{array}$ & $\begin{array}{l}\text { Value- } \\
\text { Altruism }\end{array}$ & Commitment \\
\hline Beliefs-Status & 1 & $.616^{* *}$ & .084 & .080 & .041 \\
Beliefs-Altruism & $.682^{* *}$ & 1 & .060 & $.202^{* *}$ & .062 \\
Value-Status & $.310^{* *}$ & $.299^{* *}$ & 1 & $.459^{* *}$ & $.131^{*}$ \\
Value-Altruism & $.233^{* *}$ & $.386^{* *}$ & $.303^{* *}$ & 1 & .068 \\
Commitment & .072 & $.201^{*}$ & .109 & $.173^{*}$ & 1 \\
\hline
\end{tabular}

Notes. ${ }^{*} \mathrm{p}<.05,{ }^{* *} \mathrm{p}<.01$. Female correlations below the diagonal; male above the diagonal.

\section{Structural Equation Model}

Because of the non-normality in the data, we were concerned that standard analyses would be biased. We were also interested in whether the sex differences observed in the raw correlations between summative variables would be replicated in latent variables derived from a confirmatory factor analysis (CFA). Therefore, we modeled the data using a multi-group CFA (MG-CFA) model with correlations between the latent values, beliefs, and commitment variables. See Figure 1 for the hypothesized model.

Figure 1: Hypothesized Measurement Model (CFA)

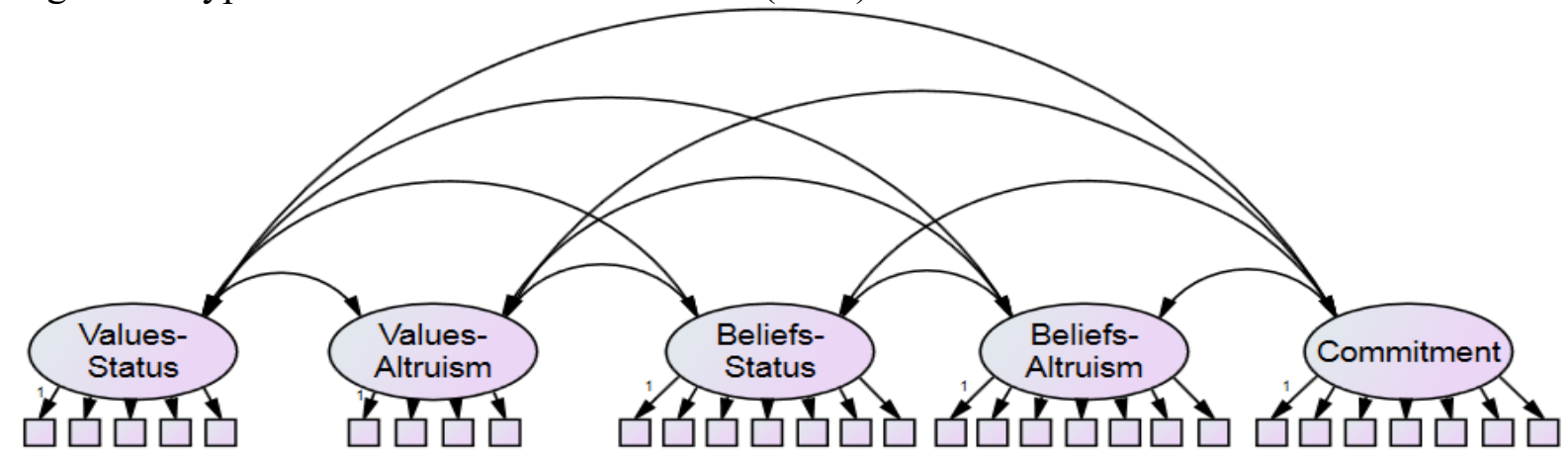

As described in the methods section, the MG-CFA method proceeds in stages where the two group models are increasingly constrained to have the same coefficients. In the first step, the hypothesized model was fitted to both groups and parameters were freely estimated. Unit loading identification was used to establish an identified model. The hypothesized model had modest to good fit. The RMSEA estimate was 0.053 (CI : $0.05-0.06$ ) which is just above the target value of 0.05. Likewise, the SRMR estimate (0.084) was just above the target 0.08 . The CFI estimate was modest at 0.73 , well below the threshold for good fit of 0.90 . Extensive efforts were madeusing modification indices and other theory-based arrangements, including a single factor for values and for beliefs - to improve model fit, but no superior model was identified. The model fits were similar for male and female samples.

The model constraint process was followed, fixing the factor loadings of items, then error variances, factor variances, and covariances. See Table 5 for model fit indices. Finally, factor means were freed. Increasing constraints had the expected impacts of slightly increasing the chisquared estimates (decreases in fit that were small relative to the change in degrees of freedom) 
and consistent improvements in the AIC/BIC estimates (which reward parsimony) and RMSEA. Increases in misfit for SRMR and CFI were minor. We concluded that full measurement equivalence (or scalar equivalence) was met in the male and female sample. In the final step, the group means were freely estimated for the two groups. This improved the fit of the model, indicating that at least some of the factor means were substantially different.

The final model estimates for correlations and means are presented in Tables 6 and 7, respectively. Importantly, the fully constrained model includes constraining the covariances between factors across gender. Therefore, in the latent model where these were constrained, no differences were found in the relationship between the values and beliefs factors and commitment to engineering. In the constrained model, all of the belief and value constructs had modest positive relationships with commitment. The mean differences replicated our findings from the manifest variables, with significant mean differences in values, with men having higher mean status value and women having higher mean altruism value.

\section{Limitations}

Self-report of attitudes and beliefs are always subject to potential biases like social desirability. In longitudinal studies there is also a concern about response-shift bias ${ }^{21}$, which refers to the problem of how participant's changing perceptions during the course of a study may affect the accuracy of earlier ratings (e.g., "not knowing what you don't know"). Because we only analyzed the pre-semester survey data, any changes in students' understanding of the survey scales as a result of the course are not reflected in our results. Our results do reflect students' incoming beliefs and attitudes about engineering prior to any intervention by the institution (because this course is the first required for pre-engineering majors).

\section{Discussion and Conclusions}

Researchers have only recently explored how individual perceptions of occupational fields like engineering can interact with individuals' personal values and goals to affect commitment to completing degrees. This line of research adds an important perspective on a new area of research in understanding why men and women differ in their engagement in and completion of engineering degrees. Because past research has treated the characteristics or affordances of fields like engineering as fixed characteristics, much research has focused on how to change the attitudes and values of women to better align with engineering. This new line of research is important because the perception of career affordances may be more malleable to interventions than individual career values. Although we did not attempt to manipulate students' perception of engineering in this study, it lays the foundation for future intervention research.

We found that, consistent with much prior work on the general population, that men and women in first-year engineering programs differ significantly in their career values, with women showing greater value for altruism and men showing greater value for status. Men and women had similar perceptions of the affordances of engineering, although there is significant variation in those perceptions, meaning that there are individual differences in how students perceive the value affordances of the field. 
Table 5: Model Fit Indices

\begin{tabular}{|c|c|c|c|c|c|c|c|c|c|c|c|c|}
\hline \multirow[b]{2}{*}{ Model } & \multirow[b]{2}{*}{$\chi^{2}$} & \multirow[b]{2}{*}{$\mathrm{df}$} & \multicolumn{2}{|c|}{ Change in $\chi^{2}$} & \multicolumn{2}{|c|}{ AIC } & \multicolumn{2}{|c|}{$\mathrm{BIC}$} & \multicolumn{2}{|r|}{ RMSEA } & \multirow{2}{*}{$\begin{array}{c}\text { SRMR } \\
\text { Est. }\end{array}$} & \multirow{2}{*}{$\begin{array}{l}\text { CFI } \\
\text { Est. }\end{array}$} \\
\hline & & & $\Delta \chi^{2}$ & $\Delta \mathrm{df}$ & Est. & $\Delta$ & Est. & $\Delta$ & Est. & $\mathrm{CI}$ & & \\
\hline 1. Model freely est'd & 1027.7 & 655 & & & 19421.9 & & 20042.9 & & 0.053 & 0.047 to 0.059 & 0.08 & 0.74 \\
\hline 2. Loadings constrained & 1037.4 & 677 & 9.7 & 22 & 19408.2 & -13.7 & 19941.1 & -101.8 & 0.051 & 0.045 to 0.057 & 0.09 & 0.74 \\
\hline 3. Item errors & 1052.9 & 704 & 15.5 & 27 & 19386.9 & -21.3 & 19811.6 & -129.5 & 0.049 & 0.043 to 0.055 & 0.09 & 0.75 \\
\hline 4. Factor variances & 1029.8 & 709 & -23.1 & 5 & 19382.8 & -4.1 & 19787.4 & -24.2 & 0.047 & 0.041 to 0.053 & 0.09 & 0.77 \\
\hline 5. Factor covar. & 1037.1 & 719 & 7.3 & 10 & 19377.6 & -5.2 & 19743.2 & -44.2 & 0.047 & 0.040 to 0.053 & 0.09 & 0.77 \\
\hline 6. Means freed & 1030.2 & 714 & -6.9 & -5 & 19352 & -25.6 & 19736.6 & -6.6 & 0.046 & 0.039 to 0.052 & 0.09 & 0.78 \\
\hline
\end{tabular}

Notes. $\Delta=$ change in that estimate. $\mathrm{CI}=$ confidence interval.

Table 6: Unconstrained and constrained correlation tables

\begin{tabular}{|c|c|c|c|c|c|c|c|c|c|}
\hline & \multicolumn{5}{|c|}{ Unconstrained latent correlations } & \multicolumn{4}{|c|}{ Constrained latent correlations } \\
\hline & $\begin{array}{l}\text { Belief- } \\
\text { Status }\end{array}$ & $\begin{array}{l}\text { Belief- } \\
\text { Altruism }\end{array}$ & $\begin{array}{l}\text { Value- } \\
\text { Status }\end{array}$ & $\begin{array}{l}\text { Value- } \\
\text { Altruism }\end{array}$ & Commit. & $\begin{array}{l}\text { Belief- } \\
\text { Status }\end{array}$ & $\begin{array}{l}\text { Belief- } \\
\text { Altruism }\end{array}$ & $\begin{array}{l}\text { Value- } \\
\text { Status }\end{array}$ & $\begin{array}{l}\text { Value- } \\
\text { Altruism }\end{array}$ \\
\hline Belief-Status & 1 & $0.88 * *$ & 0.08 & 0.05 & 0.05 & 1 & & & \\
\hline Belief-Altruism & $0.97 * *$ & 1 & 0.10 & 0.19 & 0.07 & $0.89^{* *}$ & 1 & & \\
\hline Value-Status & $0.39 * *$ & $0.33 * *$ & 1 & $0.49 * *$ & $0.19 * *$ & $0.16^{* *}$ & $0.16^{* *}$ & 1 & \\
\hline Value-Altruism & $0.32 * *$ & $0.51 * *$ & $0.28 * *$ & 1 & 0.11 & $0.11^{*}$ & $0.29 * *$ & $0.40^{* *}$ & 1 \\
\hline Commitment & $0.30 * *$ & $0.28 * *$ & $0.20 *$ & $0.28 * *$ & & $0.11^{*}$ & $0.13 * *$ & $0.20 * *$ & $0.16^{* *}$ \\
\hline
\end{tabular}

Note. For unconstrained correlations, female correlations below the diagonal, male above the diagonal.

Table 7: Latent mean differences

\begin{tabular}{lrr}
\hline Mean differences & Estimate & Sig. \\
\hline Belief-Status & 0.027 & 0.468 \\
Belief-Altruism & 0.046 & 0.119 \\
Value-Status & -0.223 & 0.001 \\
Value-Altruism & 0.304 & $<.001$ \\
\hline
\end{tabular}

Note. ${ }^{\text {a }}$ Differences are calculated as the female means in the model. To identify the model, male means are constrained to zero. 
In the latent model, all four belief and values factors significantly, though modestly, correlated with commitment to an engineering major. This indicates that understanding students' career values and perceptions of engineering may be a valuable avenue for understanding why and when students commit to an engineering major.

Efforts to change perceptions, such as the Messaging for Engineering project, may result in larger increases in diversity for engineering because it seeks to reframe engineering as a helping profession. Research in other fields has shown that messaging campaigns can be effective. ${ }^{22}$ Additionally, as the Grand Challenges are increasingly incorporated into engineering curricula $^{9,12}$, more research is needed on the degree to which Grand Challenges appeal to students, enhance interest, promote diversity, and promote persistence in engineering. In the effort to increase the number and diversity of students in engineering, such considerations of value-affordances alignment may be a critical framework for interventions.

\section{References}

1. National Science Foundation (2014). Foreign graduate enrollment in science and engineering continues to rise while overall graduate enrollment remains flat. (Publication No. NSF 14-313). Arlington, VA: National Science Foundation. Retrieved from http://www.nsf.gov/statistics/infbrief/nsf14313/

2. Lippa, R. (1998). Gender-related individual differences and the structure of vocational interests: The importance of the people-things dimension. Journal of Personality and Social Psychology, 74(4), 996.

3. Su, R., Rounds, J., \& Armstrong, P. I. (2009). Men and things, women and people: a meta-analysis of sex differences in interests. Psychological Bulletin,135(6), 859.

4. Ceci, S.J., \& Williams, W.M. (Eds.). (2007). Why aren't more women in science? Top researchers debate the evidence. Washington, DC: American Psychological Association.

5. Diekman, A. B., Brown, E. R., Johnston, A. M., \& Clark, E. K. (2010). Seeking congruity between goals and roles: A new look at why women opt out of science, technology, engineering, and mathematics careers. Psychological Science, 21(8), 1051-1057.

6. Weisgram, E.S., \& Bigler, R.S. (2007). Effects of learning about gender discrimination on adolescent girls' attitudes toward and interest in science. Psychology of Women Quarterly, 31, 262-269.

7. National Academy of Engineering [NAE]. (2008). NAE Grand Challenges for Engineering. Retrieved from http://www.engineeringchallenges.org/

8. National Academy of Engineering [NAE]. (2013). Messaging for Engineering: From Research to Action. Washington, DC: National Academies Press. Retrieved from http://www.engineeringmessages.org/

9. Vest, C.M. (2008). Context and challenge for twenty-first century engineering education. Journal of Engineering Education, 97(3), 235-236.

10. National Academy of Engineering [NAE]. (2015, March 23). “U.S. Engineering Schools to Educate 20,000 Students to Meet Grand Challenges". Retrieved from https://www.nae.edu/Projects/MediaRoom/20095/130169/134046.aspx

11. Augustine, N. R., Barrett, C., Cassell, G., Grasmick, N., Holliday, C., \& Jackson, S. A. (2010). Rising above the gathering storm, revisited: Rapidly approaching category 5. Washington, DC: National Academy of Sciences, National Academy of Engineering, Institute of Medicine.

12. Litzler, E., \& Lorah, J.A. (2013, June). A Natural Experiment: NAE's Changing the Conversation Report and Students' Changing Perceptions of Engineering. Paper presented at the ASEE Annual Conference, Atlanta, GA. Retrieved from http://www.asee.org/file_server/papers/attachment/file/0003/4391/Changing_the_Conversation_Paper_Dra $\mathrm{ft} \_$March_revision.pdf 
13. Olson, S., \& Riordan, D. G. (2012). Engage to Excel: Producing One Million Additional College Graduates with Degrees in Science, Technology, Engineering, and Mathematics. Report to the President. Retrieved from http://www.whitehouse.gov/sites/default/files/microsites/ostp/pcast-engage-to-excel-final_2-2512.pdf

14. Bouvier, S. (2011). Increasing Student Interest in Science, Technology, Engineering, and Math (STEM): Massachusetts STEM Pipeline Fund Programs Using Promising Practices. Retrieved from http://www.mass.edu/stem/documents/Student\%20Interest $\% 20$ Summary\%20Report.pdf

15. Eris, O., Chachra, D., Chen, H. L., Sheppard, S., Ludlow, L., Rosca, C., ... \& Toye, G. (2010). Outcomes of a longitudinal administration of the persistence in engineering survey. Journal of Engineering Education, 99(4), 371-395.

16. Perez, T., Cromley, J. G., \& Kaplan, A. (2014). The role of identity development, values, and costs in college STEM retention. Journal of Educational Psychology,106(1), 315-329.

17. Muthén, L.K., \& Muthén, B.O. (1998-2009). Mplus User's Guide ( $5^{\text {th }}$ edition). Los Angeles, CA: Muthén \& Muthén.

18. Chen, F. F., Sousa, K. H., \& West, S. G. (2005). Teacher's corner: Testing measurement invariance of secondorder factor models. Structural Equation Modeling: A Multidisciplinary Journal, 12, 471-492.

19. Kenny, D. A. (September 1, 2009). Multiple group models. Retrieved from http://davidakenny.net/cm/mgroups.htm

20. Kline, R.B. (2004). Principles and Practice of Structural Equation Modeling (2nd ed.). New York, NY: The Guilford Press.

21. Howard, G. S. (1980). Response-shift bias a problem in evaluating interventions with pre/post selfreports. Evaluation Review, 4(1), 93-106.

22. Tansley, D. P., Jome, L. M., Haase, R. F., \& Martens, M. P. (2007). The effects of message framing on college students' career decision making. Journal of Career Assessment, 15(3), 301-316.

${ }^{i}$ We also considered race (divided into underrepresented minorities and other students) to look for main effects or interactions with gender, but we found no significant effects. 